\title{
Reliability-based calibration of the design code for concrete structures
}

\author{
A.S. NOWAK and M.M. SZERSZEN
}

\author{
University of Michigan \\ Ann Arbor, MI 48109-2125, USA
}

\begin{abstract}
The presented study deals with the development of design code for reinforced concrete and prestressed concrete beams, slabs and columns. The major steps in the code calibration procedure include the development of load and resistance models. It is assumed that the available load models are adequate. Therefore, the main focus of this study is the verification of resistance models. A considerable database is gathered on material strength: ordinary concrete, lightweight concrete, high-strength concrete, reinforcing steel, and prestressing steel. The test results were provided by industry and they are analyzed to determine the cumulative distribution functions and other statistical parameters. It is observed that there is a considerable improvement in quality of materials during the last 20-30 years, and this results in an increased reliability of structural components. The reliability analysis is performed to determine the reliability indices for components designed according to the current code (ACI 318-99). Based on the results, the target reliability indices are selected. New load and resistance factors are recommended based on closeness to the target reliability index.
\end{abstract}

\section{Introduction}

The paper objective is to summarize the results a recent project involving the code calibration. The load and load combination factors specified in ACI 318-99 Code have not been changed since the 1950's. In the meantime, the American Society of Civil Engineers (ASCE) issued the ASCE 7 Standard on Minimum Design Loads for Buildings and Other Structures (1998). This Standard specifies loads and load combinations with corresponding load factors based on a probabilistic analysis using the statistical data on load and resistance parameters available in 1970's (Ellingwood et al. 1980). Recently, it was decided to adopt the new load factors from ASCE 7-98 for ACI 318 Code. 
The basic design formula specified by ACI 318-99 Code for a combination of dead load, $D$, and live load, $L$, is

$$
1.4 D+1.7 L<\phi R
$$

where: $R$-resistance, and $\phi$ - resistance factor.

The corresponding design formula specified in the ASCE-7 Standard is

$$
\begin{gathered}
1.4 D<\phi R, \\
1.4 D+1.6 L<\phi R .
\end{gathered}
$$

The objective of the present study is to determine the resistance factors that are consistent with load and load combination factors specified by the ASCE 7-98 Standard (Eq. (1.2)).

The calibration procedure includes five steps:

1. Selection of structural types and materials covered by ACI 318 Code.

2. Development of statistical models for load components.

3. Development of statistical models for resistance.

4. Selection of the reliability analysis procedure.

5. Selection of the target reliability indices.

6. Calculation and selection of load and resistance factors.

The main focus of this study is the verification of resistance models. They depend strongly on the statistical parameters of material properties and dimensions. A considerable database was gathered on material strength for ordinary concrete, lightweight concrete, high-strength concrete, reinforcing steel, and prestressing steel. The test results were provided by industry and they were analyzed to determine the cumulative distribution functions and other statistical parameters.

\section{Considered materials, components and limit states}

The structural types and materials covered by the ACI 318-99 Code were considered in this study. In particular, the structural types include reinforced concrete and prestressed concrete beams, slabs and columns. The limit states include bending moment capacity (for beams and slabs), shear capacity (for beams), and compression capacity (for columns). Plain concrete elements were also considered.

Materials covered in this study are:

- ordinary concrete,

- light-weight concrete (weight $<1.840 \mathrm{kN} / \mathrm{m}^{3}$ ), 
- high-strength concrete (with $f_{c}^{\prime}>45 \mathrm{MPa}$ ),

- reinforcing steel bars,

- prestressing steel strands.

With regard to the fabrication, two categories of concrete materials were considered: plant-cast (precast) and cast-in-place (ready mix concrete, constructed on a site).

\section{Load models}

The major step in the code calibration procedure is the development of load and resistance models. The statistical parameters for load components, in particular dead load and live load in buildings, were considered in the 1970's, and they are summarized by Ellingwood et al. (1980). It is assumed that the available load and load combination models are adequate for reinforced concrete and prestressed concrete components. For dead load, the bias factor is assumed equal to $\lambda=1.03-1.05$ and $V=0.08-0.10$; and for live load $\lambda=1.00$ and $V=0.20$.

\section{Resistance models}

The load carrying capacity (resistance), $R$, can be considered as a product of three factors: material properties (such as strength of material, modulus of elasticity), fabrication factor (representing dimensions, area, moment of inertia), and professional factor (analysis factor, the ratio of actual behavior to predicted by analysis).

\subsection{Concrete}

The data-base includes the results of standard cylinder tests mostly as 28 day compressive strength. However, for high-strength concrete, also 56 day strength tests were available. Statistical parameters for the considered materials (concrete and steel) were established based on the lower tail of the cumulative distribution curves. It was observed that there could be important differences in the quality of concrete, workmanship, curing procedures, and tolerances in dimensions. In this calibration, it was assumed that quality of materials and workmanship is at the average level.

The test data for ordinary concrete was obtained from ready mix companies and precasting plants. The ready mix concrete data-base included concrete strength, $f_{c}^{\prime}$, from $20 \mathrm{MPa}$ to $41 \mathrm{MPa}$, is shown in Fig. 1 , and for the plant-cast concrete $f_{c}^{\prime}$ was from $34 \mathrm{MPa}$ to $45 \mathrm{MPa}$, in Fig. 2. The presented 


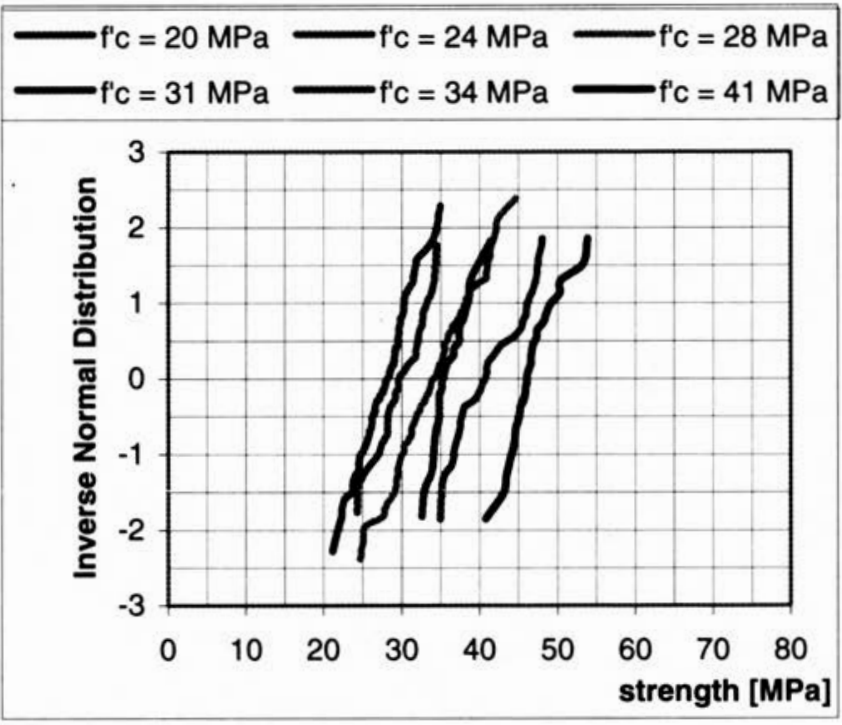

FigurE 1. CDF's for ordinary ready mix concrete.

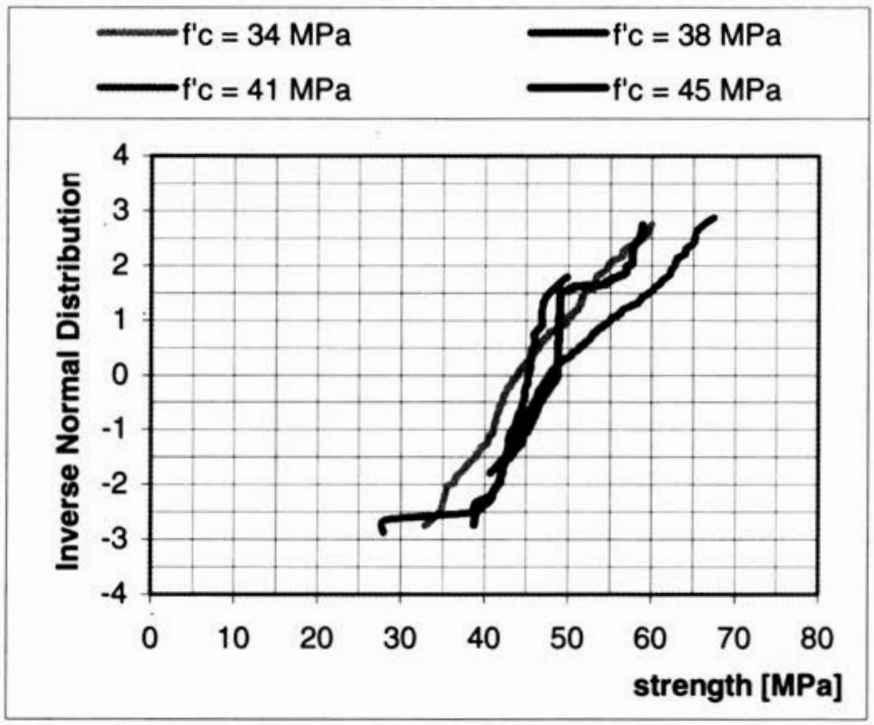

FigurE 2. CDF's for ordinary plant-cast concrete. 
CDF's include all the available samples obtained from different sources. The plotted distributions are close to straight lines, therefore they can be considered as normal distribution functions.CDF's were also prepared for high strength and light-weight concrete.Based on the test results, it is recommended to use the same bias factor, $\lambda=1.14$, for ready mix, plant-cast, high-strength, and light weight concretes. The coefficient of variation of concrete strength, $f_{c}^{\prime}$, observed in the test data is rather uniform. Therefore, it is recommended for this calibration to use $V=0.10$ for all considered types and grades of concrete.

\subsection{Reinforcing steel bars}

Reinforcing steel grade $413.4 \mathrm{MPa}$ was investigated with bar diameters from $9.5 \mathrm{~mm}$ to $34.5 \mathrm{~mm}$ (\#3 to \#11). The CDF's of yield strength, $f_{y}$, are plotted in Fig. 3. There is no trend observed in the relationship between the strength and diameter of the rebar. The CDF's for individual data files for all diameters were plotted on the normal probability paper and investigated to find the type of the distribution. In fact, all curves regardless of the diameter showed the normal distribution pattern and they are very consistent. The bias factors for reinforcing steel bars vary from $\lambda=1.125$ to $\lambda=1.20$, with all sizes except of two being within 1.14-1.165. Therefore, the recommended

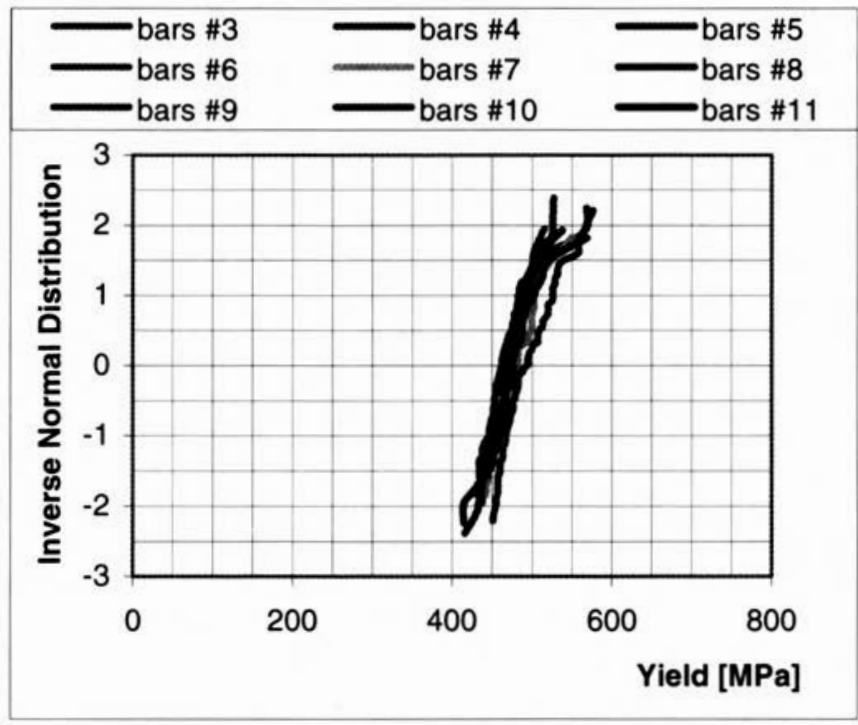

Figure 3. The CDF's of $f_{y}$ for reinforcing bars, $f_{y}=413.4 \mathrm{MPa}$. 
bias factor for $f_{y}$ rebars is $\lambda=1.145$. The coefficient of variation of $f_{y}$ varies from $V=0.035$ to $V=0.065$. The recommended coefficient of variation of $f_{y}$ for this calibration is $V=0.05$. For comparison, the bias factor for $f_{y}$ used in previous studies was $\lambda=1.125$, and coefficient of variation, $V=0.10$ (Ellingwood et al. 1980).

\subsection{Prestressing steel strands}

Two grades of prestressing steel strands were investigated: $1722.5 \mathrm{MPa}$ and $1860.3 \mathrm{MPa}$. For grade $1722.5 \mathrm{MPa}$, four strand diameters were considered, from $6.25 \mathrm{~mm}$ to $12.5 \mathrm{~mm}$, and for grade $1860.3 \mathrm{MPa}$, three diameters, from $9.5 \mathrm{~mm}$ to $12.5 \mathrm{~mm}$. The CDF's of the breaking stress are plotted in Fig. 4 for grade $1722.5 \mathrm{MPa}$. Similar CDF's were prepared for grade $1860.3 \mathrm{MPa}$.

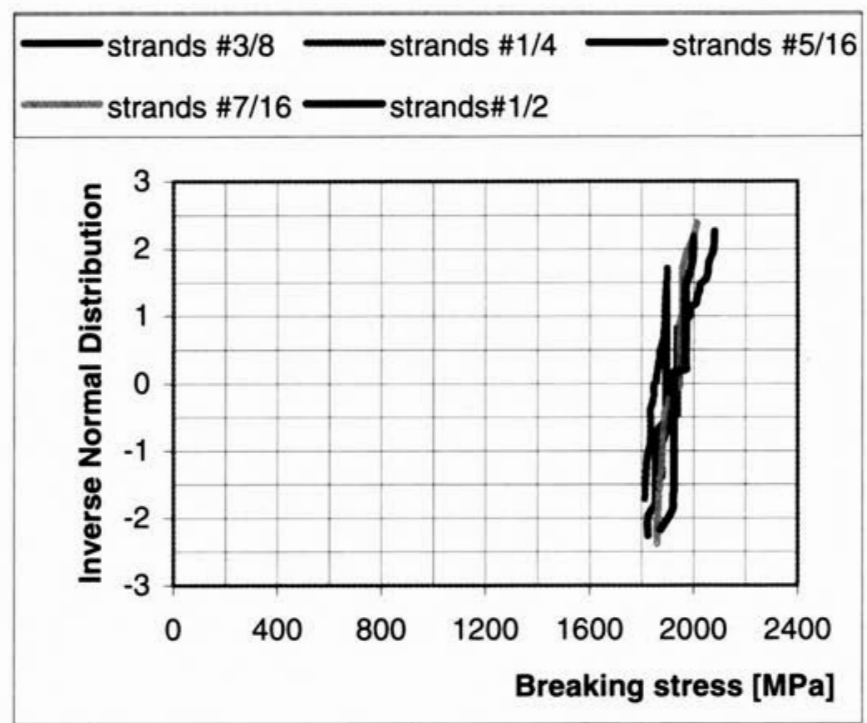

Figure 4. CDF's of breaking stress for prestressing strands. Grade $1722.5 \mathrm{MPa}$.

The bias factors for prestressing strands vary from $\lambda=1.04$ to $\lambda=1.15$. For this calibration it was recommended to use $\lambda=1.045$. The coefficient of variation varies from $V=0.007$ to $V=0.03$. It is recommended to use $V=0.025$. For comparison, the statistical parameters used in previous studies for grade $1860.3 \mathrm{MPa}$ were $\lambda=1.040$ and $V=0.025$. 


\subsection{Resistance parameters}

Fabrication factor represents the variation in dimensions and geometry of the considered structural elements. The recommended statistical parameters are based on previous studies by Ellingwood et al. (1980). For example, width $\lambda=1.01$ and $V=0.04$; depth of beams $\lambda=0.99$ and $V=0.04$; and depth of slab $\lambda=0.92$ and $V=0.12$. For reinforcing steel bars and prestressing steel strands, the bias factor of dimensions was selected as $\lambda=1.0$ and $V=0.01$. The area of reinforcing steel, $A_{s}$, was also treated as a practically deterministic value, with $\lambda=1.0$ and $V=0.015$. Professional factor is based on the results of previous studies (Ellingwood et al. 1980). The parameters of resistance, $R$, are calculated by Monte Carlo simulations.

\subsection{Reliability analysis}

The reliability indices, $\beta$, were calculated for components designed according to the "old" ACI 318 code, and based on the statistical models of resistance from 1970's. The resulting $\beta=3.40-4.65$ for reinforced concrete beams in flexure and shear, 4.25-4.40 for prestressed concrete beams, 2.352.50 for reinforced concrete slabs, $3.75-4.10$ for tied columns, $4.00-4.40$ for spiral columns, and 5.65-6.15 for plain concrete. The obtained $\beta$ 's served as a basis for the selection of the target reliability indices, $\beta_{T}$. Then, reliability indices were calculated using the new load factors (ASCE 7), and new statistical models of resistance. Several different values of the resistance factor, $\phi$, are considered. The recommended values of $\phi$ are selected to provide a close fit to $\beta_{T}$.

The resulting $\beta=3.65-4.35$ for reinforced concrete beams in flexure and shear, 4.05-4.25 for prestressed concrete beams, 2.35-2.60 for reinforced concrete slabs, $4.35-4.95$ for tied columns, $4.60-5.25$ for spiral columns, and 5.50-6.10 for plain concrete. The reliability indices for slabs are lower than for beams, and this applies to existing design and proposed design. In slabs, there is a considerable uncertainty about the actual effective depth, and the reliability index is very sensitive to any departure from the specified value of the depth. However, the overall reliability of the slab is considerably higher than the calculated value due to load sharing.

The optimum value of the target reliability index, $\beta_{T}$, can be determined based on two parameters: consequences of failure and incremental cost of safety (Nowak and Collins 2000). The code provisions in ACI 318 apply to various types of structures (components), and it is assumed that $\beta_{T}$ is to be selected for primary members (important components), and failure of a component can cause failure of other components. For secondary members, $\beta_{T}$ 
can be reduced. However, there is practically no basis available to determine the consequences of failure and cost of safety for the structural components considered in this study. Therefore, $\beta_{T}$ is selected based on the current ACI 318 Code.

It is assumed that the reliability indices for components designed using the ACI-318-99 Code are acceptable. The Code provisions have been used for over 30-40 years. Therefore, the corresponding values of $\beta$ are considered as a lower limit for acceptable values of $\beta_{T}$. For each type of component, a large variation of $\beta$ 's as a function of load ratio is an indication that the load factors are not properly selected.

The "new material data" represents the material properties determined in conjunction with this study. For most cases, the "new" parameters are improved compared to "old" data. The target reliability indices selected based on the "old" material data and ACI 318-99 Code design formula are conservatively selected as upper rather than lower limits of the range of $\beta$ obtained in calculations. The target $\beta$ 's are 3.5 for most of the components, except of $\beta_{T}=2.5$ for slabs and $\beta_{T}=4$ for columns.

\section{Load and resistance factors}

The reliability indices are subject to variation depending on load ratio. It was observed that $\beta$ is low for $L=0.15 D$. Therefore, it is recommended to change the load factors in Eq. (1.2), instead of $1.4 D<\phi R$, use $1.4(D+L)<\phi R$.

The recommended values of resistance factor are in most cases equal to $\phi$ factors specified in ACI 318-99. For example, for beams and slabs in flexure, $\phi=0.90$, beam in shear $\phi=0.85$, tied columns $\phi=0.75$, spiral columns $\phi=0.80$, and plain concrete $\phi=0.65$. This means that the required design (nominal) resistance in the code can be about $10 \%$ lower than ACI 318-99.

\section{Conclusions}

Resistance parameters are determined on the basis of material tests and other factors (fabrication and professional factors). The comparison with previous tests (1970's) confirmed that there is an improvement in quality of materials; in particular, it is observed that variation of strength is reduced. The major difference between the older data and recent results is for the strength of concrete and yield strength of reinforcing bars. The statistical parameters of prestressing strands calculated from the test data confirmed a continued trend of a very low variation. The obtained results provide a basis 
for recommended resistance factors for reinforced concrete and prestressed concrete components of building structures.

\section{Acknowledgements}

This study was sponsored by the Portland Cement Association (PCA), represented by Basile G. Rabbat, and co-sponsored by the Precast/Prestressed Concrete Institute, represented by L.S. (Paul) Johal. Their sponsorship is gratefully acknowledged. Special thanks are due to Pascal Laumet and David Ferrand for their assistance in computations.

\section{References}

1. ACI 318/99, Building Code Requirements for Structural Concrete, American Concrete Institute, Farmington Hills, Michigan, 1999.

2. ASCE 7/98, Minimum Design Loads for Buildings and Other Structures, American Society of Civil Engineers, Washington, D.C., 1998.

3. Ellingwood, T.V. Galambos, J.G. MacGregor and C.A. Cornell, Development of a Probability Based Load Criterion for American National Standard A58, NBS Special Report 577, U.S. Department of Commerce, National Bureau of Standards, 1980.

4. A.S. NowaK and K.R Collins, Reliability of Structures, McGraw - Hill, New York 2000 .

5. A.S. NowAK and M.M. Szerszen, Calibration of design code for buildings (ACI 318), Part 1: Statistical models for resistance, ACI Structural Journal (in press).

6. M.M. Szerszen and A.S. Nowak, Calibration of design code for buildings (ACI 318), Part 2: Reliability analysis and resistance factors, ACI Structural Journal (in press).

7. M.M. SzERSzEn and A.S. NowAK, Calibration of code for concrete structures, Part II, ACI Journal of Structures (in press).

8. C.J. Turkstra, Theory of structural design decisions, Solid Mechanics Study, No.2, University of Waterloo, Waterloo, Canada 1970. 